\title{
A fragilização dos vínculos familiares dos adolescentes em liberdade assistida
} The weakening of family bonds among adolescents in probation

\section{La debilitación de los lazos familiares de los adolescentes en libertad asistida}

\author{
Recebido: $13 / 04 / 2020$ \\ Aprovado: 15/10/2020 \\ Publicado: 05/11/2020
}
Luciano Aparecido Pereira Junior ${ }^{1}$ Matheus Colombari Caldeira ${ }^{2}$ Thercius Oliveira Tasso ${ }^{3}$ Regina Célia de Souza Beretta ${ }^{4}$

Este é um estudo qualitativo e de campo realizado em 2019 numa cidade de pequeno porte do interior paulista, com o objetivo de descrever as relações familiares de adolescentes em liberdade assistida e as violações e violências vividas. Os métodos foram compostos por uma intervenção por meio de uma Oficina de Promoção da Saúde e da Cultura da Paz, além de seis grupos focais, entrevista com pais e responsáveis e análise dos Planos Individuais de Atendimento, com participação de 12 adolescentes. Duas categorias emergiram: Família e Violência. As relações familiares com os adolescentes evidenciam a fragmentação e rompimento de vínculos afetivos, e perpassam problemas sociais que afetam diretamente estes indivíduos, como o acesso ou o não acesso aos serviços de saúde, assistência social e educação, além do emprego, renda, saneamento básico e diversos outros fatores sociais, como raça, sexo e gênero. Na questão da violência verificou-se: conflitos frente aos agentes da segurança, temor pelo espaço público, negação do direito de ir e vir, abuso sexual de crianças e violência contra a mulher. Nas construções familiares dos adolescentes em cumprimento de medidas socioeducativas, aponta-se a importância da implementação da Cultura da Paz, perpassando pela capacitação dos profissionais, estruturação dos serviços e órgãos, democratização do processo de tomada de decisão e participação ativa de todos os atores.

Descritores: Adolescente; Família; Promoção da Saúde.

This is a qualitative field study carried out in the year of 2019 in a small city in the interior of the state of São Paulo. It aimed to describe family relationships of adolescents in probation and the violations and violence they have experienced. The methods consisted of an intervention through a Health Promotion and Culture of Peace Workshop, in addition to six focus groups, interviews with parents and guardians and analysis of Individual Care Plans, with the participation of 12 adolescents. Two categories emerged: Family and Violence. Family relationships with adolescents show fragmentation and disruption of affective bonds, and permeate social problems that directly affect these individuals, such as access or non-access to health services, social assistance and education, in addition to employment, income, basic sanitation. and several other social factors, such as race, sex and gender. In the issue of violence, there were: conflicts with security agents, fear for the public space, denial of the right to come and go, sexual abuse of children and violence against women. In the family constructions of adolescents in compliance with socio-educational measures, the importance of implementing Culture of Peace is highlighted, including training of professionals, structuring of services and bodies, democratization of the decision-making process and active participation of all agents.

Descriptors: Adolescent; Family; Health Promocion.

Este es un estudio cualitativo y de campo realizado en 2019 en una pequeña ciudad del interior de São Paulo, con el objetivo de describir las relaciones familiares de los adolescentes en libertad asistida y las violaciones y las violencias experimentadas. Los métodos se compusieron de una intervención a través de un Taller de Promoción de la Salud y Cultura de Paz, además de seis grupos focales, entrevista con padres y representantes y análisis de los Planes Individuales de Asistencia, con la participación de 12 adolescentes. Surgieron dos categorías: Familia y Violencia. Las relaciones familiares con los adolescentes muestran la fragmentación y ruptura de los lazos afectivos, y pasan por problemas sociales que afectan directamente a estos individuos, como el acceso o no a los servicios de salud, asistencia social y educación, además del empleo, los ingresos, el saneamiento básico y varios otros factores sociales, como la raza, el sexo y el género. Con relación a la violencia se observó: conflictos con los agentes de seguridad, miedo al espacio público, negación del derecho a ir y venir, abuso sexual de niños y violencia contra las mujeres. En las construcciones familiares de los adolescentes en cumplimiento de las medidas socioeducativas, se señala la importancia de la implementación de la Cultura de Paz, pasando por la formación de profesionales, la estructuración de servicios y órganos, la democratización del proceso de toma de decisiones y la participación de todos los actores.

Descriptores: Adolescente; Familia; Promoción de la Salud.

1. Psicólogo. Especialista em Psicologia Jurídica e Avaliação Psicológica. Especialista em Psicanálise. Mestre em Promoção de Saúde. Doutorando em Promoção da Saúde pela Universidade de Franca (UNIFRAN), Franca, SP, Brasil. ORCID: 0000-0002-0310-1865 E-mail: lucianojuniorpereira@gmail.com

2. Psicólogo. Especialista em Psicanálise. Mestrando em Psicologia e Saúde pela Faculdade de Medicina de São José do Rio Preto, SP, Brasil. ORCID: 0000-0003-1892-5450.E-mail: mmatheuscaldeira_@hotmail.com

3. Farmacêutico. Pós-doutorando em Promoção de Saúde pela UNIFRAN, Franca - SP, Brasil. ORCID: 0000-0003-1233-8909 E-mail: thercim@gmail.com

4. Assistente Social. Pedagoga. Especialista em Gestão Pública e Gerencia de Cidades. Mestre e Doutora em Serviço Social. Professora do Programa de Pós-Graduação em Promoção de Saúde da UNIFRAN, Franca, SP, Brasil. ORCID: 0000-0003-2817-0805 E-mail: regina.beretta@unifran.edu.br 


\section{INTRODUÇÃO}

A

s medidas socioeducativas são aplicadas a adolescentes que cometeram algum tipo de ato infracional, se diferindo de crime dentro do que estabelece o Estatuto da Criança e do Adolescente (ECA). Dentro das medidas existentes, duas modalidades são cumpridas dentro do Centro de Referência Especializado de Assistência Social (CREAS), sendo elas a Prestação de Serviços à Comunidade (PSC) e a Liberdade Assistida (LA), que é definida como umas das medidas a serem aplicadas com o intuito de acompanhar, auxiliar e orientar o adolescente, sendo esta fixada pelo prazo mínimo de seis meses, podendo ser prorrogada, revogada ou substituída conforme propor a autoridade judicial ${ }^{1}$.

A Cultura da Paz (CP) pode ser conceituada pelo processo de retirada da violência enquanto norteadora de um discurso para a inserção da paz como mediadora do processo das relações sociais saudáveis a serem estabelecidas, o que pede uma rede de atenção e proteção social em pleno funcionamento, envolvendo diversos atores e políticas públicas ${ }^{2-4}$.

A CP implica na mudança de comportamento e pensamento das pessoas, e tem o intuito de garantir e estabelecer a paz pela justiça restaurativa e a mediação dos conflitos familiares para evitar a judicialização dos processos, criando assim um espaço dialógico em que todos os integrantes da família possam se expressar sobre suas vivências cotidianas e suas necessidades ${ }^{2-4}$.

A Política Nacional de Promoção de Saúde (PNPS) enfatiza a intersetorialidade e a interdisciplinaridade, propondo ações conjuntas e efetivas de profissionais de diversas áreas, além da capacitação dos profissionais e, em especial, da saúde, assistência social e educação ${ }^{2}$. Isto pois, para a mediação dos conflitos, há a necessidade de articulação com outras políticas públicas, além "da participação social e dos movimentos populares, em virtude da impossibilidade de que o setor saúde responda sozinho ao enfrentamento dos determinantes e condicionantes da saúde"2.

A Carta de Ottawa ${ }^{5}$, um dos principais documentos internacionais de promoção de saúde e que influenciou o pensamento brasileiro para a reforma sanitária e construção do Sistema Único de Saúde (SUS), já apontava a necessidade de descentralização de ações no campo da saúde, de capacitação das equipes profissionais, do empoderamento e advocacy da participação social e de justiça social.

O conceito de empoderamento deve ser visto não como forma de dar poder a alguém, mas sim como ferramenta para a criação de um espaço dialógico em que os discursos construídos possam dar representatividade àquele determinado grupo, e cujo advocacy junto à justiça social deve zelar pela defesa dos direitos estabelecidos nas leis vigentes no Brasil 5 .

Além da Carta de Ottawa, os Objetivos do Desenvolvimento Sustentável (ODS) da Agenda $2030^{6}$ colocam a importância de todos países buscarem o equilíbrio entre desenvolvimento econômico, social e ambiental. Os ODS tem como meta a garantia universal dos direitos humanos a todos.

Entre as 17 propostas estabelecidas pela Organização das Nações Unidas (ONU), o ODS número 16 destaca a importância de se "promover sociedades pacíficas e inclusivas para o desenvolvimento sustentável, proporcionar o acesso à justiça para todos e construir instituições eficazes, responsáveis e inclusivas em todos os níveis"6, o que corrobora a PNPS ao estabelecer o pressuposto da CP, no âmbito brasileiro5,6. A promoção da saúde se realiza por meio de um conjunto de estratégias e formas de produzir saúde no âmbito individual e coletivo, visando atender às necessidades da população e contribuir para a melhoria da qualidade de vida da população.

Nos projetos e ações afirmativas de direitos humanos nos territórios para se implementar a $\mathrm{CP}$, é necessário compreender de forma dinâmica e próxima os indivíduos que nele vivem, além de envolver diretamente as famílias e adolescentes na proposta. Entender que cada família pode ser considerada um microgrupo e funciona de uma determinada forma pode contribuir na ampliação do olhar, e também compreender que estas possuem padrões, 
papeis e funções estabelecidas socialmente e pelo próprio grupo que devem ser respeitados e trabalhados por meio da mediação de conflitos e problemas e oferta de oportunidades para resgatar direitos anteriormente violados.

As configurações e estruturas familiares patriarcais têm se modificado ao longo do tempo. Os novos arranjos familiares podem ser constituídos por casais heterossexuais, mulheres solteiras, pais solteiros, casais homossexuais, avós que zelam pelos netos, tios que cuidam dos sobrinhos e diversas outras maneiras que podem ser resignificadas e conceituadas como família. Além disso, há uma expansão no papel das mulheres enquanto provedoras financeira e afetivamente de sua casa, dando um caráter ao matriarcado cada vez mais instalado ${ }^{7}$.

A família atual encontra um espaço de pluralidade mediante as diversas relações estabelecidas. 0 conceito de família deixou de ser abordado como "família-instituição" e passou a ser definido por "família-instrumento", em que se preza pelo desenvolvimento do ser humano, protegido e resguardado pelos direitos existentes ${ }^{8}$.

A família nuclear pode ser identificada por aquelas pessoas que vivem na mesma casa, e este conceito deve ser considerado independente da sua constituição e estruturação familiar. Já a família extensa inclui avós, tios, primos e outros que não convivem em um mesmo espaço ${ }^{7,8}$.

A família pautada pelo casamento, patriarcado, hierarquizada, heteroparental, biológica e institucional deu lugar a uma nova configuração familiar, baseada na pluralidade, na democracia, na igualdade, nas formas hetero e homoparental, seja ela biológica ou sócioafetiva, que se constrói e se fundamenta na afetividade e na instrumentalidade ${ }^{7}$.

Estes novos arranjos familiares com uma nova concepção de família só foram possíveis mediante a quebra paradigmática para uma nova construção social, no entanto, ainda se carece uma compreensão maior sobre os papeis e funções estabelecidas dentro de cada grupo familiar.

Para a família, a rede de proteção composta por diversos serviços e profissionais deve agir de forma conjunta, e estes espaços devem ter seus vínculos reconstituídos e reconstruídos. A CP apresenta uma conceituação essencial: a mediação de conflitos viabilizada pela justiça restaurativa, que não está presente em todos os espaços, mas tem se solidificado e se ampliado por diversas cidades ${ }^{3,4}$.

A realidade das famílias dos adolescentes que cometeram um ato infracional demonstra, além da vulnerabilidade e fragilidade existente, outros problemas, que ocorrem mediante a negação de direitos, exacerbando a situação de risco pré-existente. Há uma negação inicial do cometimento do ato infracional por parte dos pais frente aos filhos e a sensação de impotência nos problemas sociais, que extrapola os domínios das relações familiares. Por sua vez, o ato infracional pode estar associado ao consumo constante de drogas lícitas e ilícitas ${ }^{4}$.

Aos serviços, como o CREAS $^{9}$, cabe, além de atender o adolescente infrator, dar suporte aos familiares em seus territórios. O CREAS articula o trabalho intersetorial, especialmente junto os Centros de Referência da Assistência Social (CRAS), as Organizações Não Governamentais (ONGS), as Unidades Básicas de Saúde (UBS) e as unidades de educação, além de equipamentos e espaços públicos disponíveis para a prática de cultura, esporte e lazer.

0 intuito é propiciar às famílias uma proteção social especial, garantindo direitos sociais, enfrentando qualquer tipo de violação e negligência existente. A exclusão social com que convivem deve ser superada, principalmente pela transferência de renda e acesso aos serviços públicos.

Apesar das dificuldades ou resistências de adesão aos serviços, os profissionais precisam aproximar-se das necessidades vividas pelos adolescentes e famílias para identificar e superar, nos territórios, as vulnerabilidades que se apresentam. Assim, este estudo tem como objetivo descrever as relações familiares de adolescentes em liberdade assistida e as violações e violências vividas. 


\section{MÉTODO}

Este é um estudo qualitativo e de campo, que possibilita a inserção em determinado ambiente e propicia o contato direto com os sujeitos pesquisados ${ }^{10}$. Foi realizada uma revisão integrativa em seis etapas, sendo a primeira àquela que consistiu na pergunta norteadora da pesquisa, sobre a efetividade da CP frente ao ato infracional e a violência.

A segunda etapa perpassou as plataformas de busca e pesquisa, como o Google Acadêmico, Pepsic, Redalyc e Scielo, e documento oficiais do governo brasileiro e internacionais, por meio dos descritores em saúde: adolescentes, medidas socioeducativas, promoção da saúde e cultura da paz.

A próxima etapa se configurou na coleta dos dados. A quarta e quinta etapa perpassou a análise crítica dos materiais coletados e discussão dos dados, enquanto a última consistiu na apresentação das informações coletadas. Houve também uma pesquisa documental baseada no Plano Individual de Atendimento (PIA) dos adolescentes, sendo este um documento importante, preenchido pelo técnico de referência em conjunto com ele e sua família, em que ali se estabelece o histórico de vida daquela família, além das perspectivas e metas que podem ser alcançados durante o processo de cumprimento de medidas socioeducativas.

O estudo foi realizado em 2019, entre os meses de agosto e outubro, no CREAS de uma cidade de pequeno porte, localizada no interior do estado de São Paulo, com uma população de cerca de 80 mil habitantes, caracterizada pelo cultivo da laranja. O CREAS se encontra na região central e atende duas modalidades de cumprimento de medidas socioeducativas; a Liberdade Assistida (LA) e a Prestação de Serviço à Comunidade (PSC).

O CREAS como equipamento público estatal no âmbito da proteção social especial está vinculado à Política Nacional de Assistência Social, que visa o atendimento de pessoas e famílias em situação de risco e vulnerabilidade social, com laços familiares fragilizados pela violência e direitos violados. No CREAS, são oferecidos: serviços de proteção e atendimento especializado a famílias e indivíduos, medidas socioeducativas de meio aberto, abordagem social para pessoas em situação de rua, e ainda serviços para pessoas com deficiência, idosas e suas famílias 9 .

As medidas socioeducativas de meio aberto são de responsabilidade do município, como prevê o Sistema Nacional de Atendimento Socioeducativo (SINASE), num processo de descentralização que deve envolver principalmente a assistência social, a saúde, a educação e outros, bem como: a Vara da Infância e Juventude, a Defensoria Pública, os Conselhos de Direitos e o Conselho Tutelar na disponibilização e acesso aos serviços por parte dos adolescentes e suas famílias.

Inicialmente, houve um primeiro contato com os adolescentes com ao menos três meses de LA para que conhecessem a pesquisa e demonstrassem ou não o interesse em participarem dela. Aqueles que aceitaram, em um segundo momento, participaram da Oficina de Promoção da Saúde e Cultura da Paz, com duração de uma hora e meia, para que pudessem conhecer a temática, antes de integrarem os grupos focais, num processo de conhecimento e reconhecimentos destes termos no cotidiano de suas vidas ${ }^{11}$.

Posteriormente, foram desenvolvidos seis grupos focais, priorizando o coletivo e a construção em grupo, podendo o pesquisador utilizar disparadores para que os diálogos pudessem fluir de forma contínua durante a coleta dos dados, de modo que fosse possível que os sujeitos envolvidos reconhecessem no grupo realidades parecidas e compreendessem as demandas e necessidades uns dos outros ${ }^{12,13}$. Durante o grupo, as falas dos participantes foram gravadas para posterior transcrição e categorização do material. As categorias de análise puderam ser estabelecidas previamente pelo pesquisador, de modo que este já possuía certo contato e proximidade com o tema abordado ${ }^{14}$.

Nas etapas seguintes, foram realizadas as entrevistas por pautas com os pais e responsáveis dos adolescentes, tendo estas caráter semiestruturado, em que o entrevistado pode falar livremente, mas sem que se perca o foco da temática estabelecida ${ }^{15}$. As pautas 
propostas foram a caracterização da família, o acesso às políticas públicas, dificuldades nos territórios e as violações aos direitos vividas. As entrevistas também foram gravadas e transcritas posteriormente.

Como última etapa da coleta de dados, houve a análise documental, que é "um conjunto

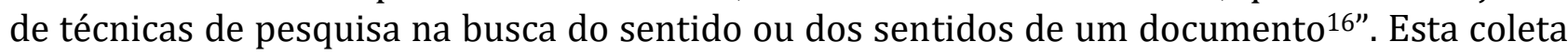
foi possível por meio do PIA, com o intuito de conhecer ainda mais as famílias e vivências dos adolescentes, além de suas perspectivas futuras.

A análise de conteúdo se deu à partir do estudo e leitura concisa das transcrições realizadas, das experiências vivenciadas em cada grupo e entrevista, e também com as informações contidas no PIA e contraste com produções na área. A análise de conteúdo foi um processo sistemático, minucioso e compreensivo ${ }^{15}$.

0 processo de análise foi realizado por meio de leitura atenta de cada transcrição feita; das relações entre os discursos, os temas propostos e o aporte teórico; pela observação do funcionamento dos grupos e o comportamento dos adolescentes; e o que foi possível compreender mediante o processo de interpretação dos dados e contraste com a área temática ${ }^{17}$.

Como referencial se usou o Construcionismo Social, voltado para o cotidiano e para o processo de construção de conhecimentos por meio dos discursos e experiências, como uma forma de intercâmbio social ${ }^{18}$.

Para a proteção dos participantes, o pesquisador foi caracterizado por $\mathrm{PE}$, os adolescentes pela letra $\mathrm{P}$, seguida de um número, as mães pela letra $\mathrm{M}$ e o único pai participante da pesquisa, com a letra $\mathrm{F}$, também seguidas de um número que remete ao mesmo número de seus filhos.

O projeto foi submetido e aprovado pelo Comitê de Ética e Pesquisa da Universidade de Franca (UNIFRAN), sob o CAAE no 03384018.9.0000.5495, considerando as determinações das pesquisas com seres humanos, prevista pela resolução no 466/12 do Conselho Nacional de Saúde e a Resolução no 007/2003 do Conselho Federal de Psicologia sobre o arquivamento de documentos e relatórios. Além, da posse dos Termos de Consentimento Livre e Esclarecido (TCLEs) assinados pelos pais e responsáveis e dos Termos de Assentimento assinados pelos adolescentes. A participação dos adolescentes também foi condicionado a autorização judicial.

\section{RESULTADOS}

A pesquisa contou com a participação de 12 adolescentes em cumprimento de medidas socioeducativas com idade entre 14 e 17 anos, sexo masculino e feminino, além dos seus pais e responsáveis.

As categorias elencadas foram: Família, Violência, Serviços Disponíveis, Direitos e Deveres do Adolescente, Relações Sociais e Cultura da Paz. No entanto, para este estudo se abordará somente as categorias Família e Violência.

\section{Família}

As falas mostram a conceituação da palavra família, as formações familiares e as relações transgeracionais características destas famílias.

P11: Meu pai e minha mãe. É importante porque faz bem, né.

P1: Minha mãe e minha irmã. Ela me dá estrutura, né.

As relações quanto à família extensa e seu funcionamento:

M6: Eu começo a chorar, porque, é meio complicado. Bem, eu sou filha... Eu tenho pai e tenho mãe e tenho mais três irmãs. Só que eu nunca me dei bem com nenhum deles.

M1: Minha família não é muito ligada, assim.

A ausência da figura paterna:

P5: Não o conheci. Meu pai me abandonou quando eu era pequenininho.

P6: Eu moro longe do meu pai porque ele está preso. Se não era para a gente estar junto.

A mãe, enquanto sustento financeiro e afetivo da família e as novas configurações familiares: 
M12: Porque, eu acho que o erro meu foi de eu não bater, porque como eu apanhei muito na infância, eu era muito arteira, meus pais achavam que bater resolvia a solução, e eu achava que não, você sentar e conversar era uma solução, só que não está resolvendo. (Pede desculpa e chora)

Foi possível observar também nos discursos dos adolescentes e dos pais, um distanciamento e até mesmo uma ruptura na família nuclear e/ou da família extensa. Os adolescentes revelaram uma forte vinculação com a figura materna como a pessoa mais importante em suas vidas, se abalando diante das situações de violações.

As relações familiares com os adolescentes evidenciam a fragmentação e rompimento de vínculos afetivos e perpassam problemas sociais que afetam diretamente estes indivíduos, como o acesso ou o não acesso aos serviços de saúde, assistência social e educação, além do emprego, renda, saneamento básico e diversos outros fatores sociais, como raça, sexo e gênero.

\section{Violência}

As relações de invasão de propriedade, privacidade e a arbitrariedade da segurança pública:

M1: Antes de eu vir mesmo os policiais pegaram meu filho, que estava sentado na porta de casa, ouvindo música com fone de ouvido.

M4: Eu vi quando pegaram [P4]. $O$ rosto dele estava todo inchado. Bateram no rosto dele. E falaram para o [P4]: se falar que a gente te bateu, a gente volta. Assim, então cria uma revolta neles. Eles estão errados? Não estão certos. Mas acaba criando uma revolta neles.

A violência reconhecida e exposta nos discursos:

P2: Quando o cara soca a mão na sua cara "néh"!

P1: Everbal.

PE: E vocês vivenciam isso em que momento?

P1: Em qualquer lugar, qualquer lugar.

A violência contra a mulher dentro dos territórios:

P3: Já vi várias vezes. É normal. Hoje em dia é normal. Mas não pode não néh?! Eu não acho certo não.

As desigualdades existentes:

P2: Não também. Não tem igualdade. O filho de rico não é tratado igual filho de pobre. Nos faz sentir mais inseguros. É o que deixa nós inseguro. É, nós não tem liberdade.

A maioria dos adolescentes em cumprimento de medidas socioeducativas aqui descrita cometeu o ato infracional de tráfico de drogas, além de parte deles fazerem uso de algum tipo de droga lícita e ou ilícita, em especial álcool e maconha. Destaca-se ainda o uso de drogas presente nas próprias famílias e o fato de alguns pais estarem presos por diversos crimes cometidos, entre eles, o próprio tráfico.

\section{DISCUSSÃO}

$\mathrm{Na}$ temática Família, os adolescentes demonstraram uma dificuldade explícita em nomear a palavra "família" e conceituá-la frente à sua importância ou não para ele, bem como a demonstração de sinais de fragilidade e de rompimentos expressivos com ao menos um dos integrantes da família, como o pai.

A ausência da figura paterna esteve presente diretamente nas falas dos adolescentes. Além dos aspectos de transgeracionalidade no uso de drogas, nas prisões e nos rompimentos de vínculos com a família extensa. A função paterna pode ser estabelecida por qualquer pessoa que se configure enquanto àquele que nomeia as leis e os limites dados à criança e ao adolescente, como a própria mãe ${ }^{19}$. No entanto, é essencial observar que, neste cenário, a ausência do pai, enquanto figura masculina socialmente estabelecida aparece nos discursos destes que o perdem, enquanto referência e vivenciam o luto deste distanciamento ${ }^{20}$.

Novas configurações e composições familiares devem ser compreendidas. Aqui, o foco não se mantém na genitora ou genitor, mas naqueles que exercem a função de cuidado e proteção. As funções materna e paterna não estabelecem foco sobre o pai e a mãe ou o homem e a mulher, mas nos papéis e representações sociais. A avó pode exercer uma função paterna, tanto quanto, em um casal homossexual que podem ter qualquer uma das funções, prezando 
sempre pelo cuidado com a criança e/ou adolescente. Deve-se quebrar o paradigma de um modelo de família socialmente imposto fundamentado no ultrapassado patriarcado ${ }^{7,8}$.

Nesta linha de construção do conhecimento grupal emergiu a necessidade de falar sobre autocuidado e autoconhecimento, além das atitudes dos adolescentes frente às suas famílias e como o uso de determinada droga, em sua maioria a maconha, afeta diretamente a realidade destas famílias, além do tráfico e da influência deste nos territórios.

As famílias também apresentaram adoecimento ao longo do tempo, como casos de: câncer, depressão, ansiedade e síndromes, desnutrição.

A família sempre foi vista como de extrema importância, por aqueles que assim a definiram. No entanto, os conflitos familiares foram enfatizados nos discursos dos pais, pela fragmentação na relação com os próprios pais e irmãos (família extensa). Para as mães, os distanciamentos causavam sofrimento e sentimento de "ausência" e saudade.

Novas configurações e composições familiares são observadas nas famílias compostas por matriarcas como fonte de cuidado, proteção e renda. Já a relação com os pais é distante, especialmente quando moravam em casas distintas. A ausência da função paterna, enquanto aquela que representa a lei e o limite sob o aspecto psicossocial, se configura em uma perda de referência para estes sujeitos, além das normas sociais existentes em que se impõe a disciplina e se padroniza um comportamento social "desejável" ou "aceitável"20.

Os adolescentes se questionavam... Quem é o meu pai?, Porque fui abandonado?, e as falas refletiam uma ausência ainda refletida nos comportamentos e ações. Um luto ainda mal elaborado, de alguém que se foi ou se ausentou. Este aspecto esbarra ainda no sentido que o sujeito dá a si mesmo: Quem sou eu? que reflete nos conceitos de autonomia e de autoconhecimento ${ }^{20}$. Por outro lado, verificou-se que parte dos adolescentes conhece o pai, mas não possuem nenhum vínculo com o mesmo.

Compreender estes aspectos de funcionalidade é essencial para se entender como os adolescentes elaboram essa estrutura no ambiente ao seu redor ${ }^{7,8}$. A compreensão familiar e de sua dinâmica, explicita o conhecimento dos sujeitos, de suas condições socioeconômicas e aspectos culturais nos quais estão inseridos. 0 que se observou forma famílias sem o genitor, permeada de dificuldades financeiras, em que a mãe se ausenta para o trabalho e se sobrecarrega do cuidado com a casa e seus filhos 20,21 .

Os conflitos familiares também estão descritos no PIA pelo técnico de referência do CREAS, que é o profissional que acompanha o adolescente e sua família durante o cumprimento da medida socioeducativa. No PIA, verificou-se discussões conflituosas, apontadas durante as entrevistas iniciais, para cumprimento da medida socioeducativa. Nestes eventos com os pais, em casa, os adolescentes preferiam sair de casa para que as coisas se apaziguassem, e faziam o uso de alguma substância lícita ou ilícita para se acalmarem.

A droga se torna um refúgio de um ambiente instável, que gera adoecimento a todos os que ali convivem e torna-se estratégia de mediação entre o mundo interno e o externo, com o intuito de alcançar a sobrevivência frente a uma liberdade inexistente, visto que se sentem inseguros para ir e vir em uma sociedade que não atende a este direito essencial, possibilitado pelo contexto democrático. 0 adolescente deseja se revestir de si mesmo, mesmo que seja por um único momento ou trago, mas sabendo que, a longo prazo, estas ações poderão custar a sua saúde e a sua liberdade, havendo uma "fuga" da realidade frente as violências e vulnerabilidades vividas.

As relações parentais e sociais são formadoras de sujeitos. Os adolescentes em cumprimento de medida socioeducativa vivem em exclusão social e buscam em "seus pares" uma forma de se fortalecer. Pode-se observar e evidenciar o quanto os conflitos familiares refletem a dinâmica social que se impõe ao redor de cada família ${ }^{21}$. É preciso compreender que os laços familiares não demandam por uma norma ou padrão pré-estabelecidos, mas se tornam possíveis no espaço dialógico ampliado e quando as pessoas se reconhecem, enquanto indivíduos, com suas próprias características. 
Entender as famílias demanda um olhar mais crítico, que ultrapassa as barreiras das condições socioeconômicas para considerar os aspectos culturais, étnicos, sexuais, de gênero, exclusão social, do uso substâncias psicoativa, das violências domésticas e da inserção ou não dos indivíduos no mercado de trabalho, além da informalidade predominante na realidade da população de baixa renda no Brasili22.

As condições de moradia das famílias, a baixa escolaridade dos pais e a evasão escolar dos filhos foram aspectos também abordados. Embora a maioria das moradias fosse própria, só foram conquistadas por meio de programas sociais habitacionais graças às parcerias entre os governos municipais, estaduais e federais. Além disso, em diversos casos, a sobrevivência das famílias dependia de algum benefício que um dos integrantes recebe, como o Benefício de Prestação Continuada (BPC), Bolsa Família ou ainda Renda Cidadã.

Com relação ao sistema de proteção social e os benefícios sociais, como transferências de renda, não eram todas as famílias e indivíduos que tinham acesso. Acrescenta-se que era comum o desemprego, a renda insuficiente, a baixa escolaridade, as dificuldades de aprendizagem dos filhos (que contribuía para a evasão escolar), considerando que o acesso à educação é uma das formas efetivas e essenciais para se superar os ciclos de pobreza. Havia ainda uma demanda pela capacitação dos profissionais que atendem essa população, buscando por meio da CP, estratégias e ações que viabilizassem o bem-estar e a qualidade de vida ${ }^{3}$.

Além da questão transgeracional, torna-se pertinente a posição que o Estado ocupa em negligenciar as necessidades familiares e privar os sujeitos de seus direitos constitucionais, em vez de garantir uma proteção social sólida e efetiva. A família deve ser vista como um microssistema dentro de macrossistemas, e que cada vez se amplia e sofre interferências ${ }^{19}$. Cada ação ou decisão tomada em uma esfera destes sistemas influencia diretamente os demais grupos, que nem sempre estão preparados para lidar com determinada situação.

o CREAS também atendia as famílias buscando ampliar a compreensão sobre as violências vividas como um processo cíclico e continuo, em que o sujeito violado, se não receber nenhum suporte, pode vir também a violar. Este serviço é importante no trabalho social realizado, fortalecendo vínculos e mediação dos conflitos existentes como ponto fundamental que se enquadra dentro da CP e sua inserção ${ }^{22,23}$.

Entretanto, a precarização dos serviços e a sobrecarga dos poucos profissionais neles existentes, principalmente no trabalho com as medidas socioeducativas dificulta a qualidade e efetividade do trabalho a essa população, além de não corroborar para a CP.

É primordial compreender que o $\mathrm{ECA}^{1}$ garante como direito fundamental à criança e ao adolescente ter uma família e nela estar inserida. Quando se pensa na CP, esta não é possível diante de conflitos familiares, violências intrafamiliares, ruptura de vínculos, problemas no território e na comunidade e violações de direitos, que fortalecem ainda mais a reprodução e mediação da violência, e não a da paz.

É preciso que se estabeleça uma proteção integral efetiva ${ }^{24}$, em que o Estado deve garantir a estas famílias as condições mínimas de sobrevivência, desenvolvimento e sustentabilidade. E, para que isso aconteça, as políticas públicas devem ser estabelecidas de forma que todos os direitos previstos na Constituição sejam garantidos, e que todas as demandas e necessidades sejam sanadas de forma equitativa, conforme cada realidade apresentada. Ressalta-se a ação das políticas em saúde, assistência social e do Sistema de Garantia de Direitos (SGD) parte do princípio da universalidade e abre portas para a garantia de uma CP estabelecida.

A Violência deve ser compreendida como um fenômeno social e histórico presente na humanidade, mas que de forma alguma deve ser aceita. Em diversas situações ao longo do crescimento do Brasil, vários direitos foram violados, além de fatores de risco e iniquidades em saúde 25 . 
A violência é um problema de saúde pública, mas não apenas dela. Todas as políticas públicas devem conversar entre si, inclusive profissionais e serviços, que devem exercer um trabalho intrasetorial, intersetorial e interdisciplinar, englobando um processo construtivo e de mediação frente aos discursos, necessidades e demandas ${ }^{26}$.

Os grupos focais com os adolescentes e as entrevistas com os pais e responsáveis apontaram um enredo de uma violência praticada pelos agentes de segurança pública, principalmente em suas formas de abordarem os sujeitos e entrarem em suas casas, o que gera situações de constrangimento e até mesmo de perseguição.

Também verificou-se: a ineficiência dos diversos órgãos e serviços de proteção social, a negação de vagas em escolas públicas, as dificuldades do Conselho Tutelar em garantir os direitos estabelecidos no ECA, a falta de qualificação profissional e, ainda, a demanda pelo acesso ao mercado de trabalho, na qual impera o consumo e os desejos dos sujeitos frente ao sistema capitalista vigente. Além disso, foram identificados preconceitos por residir em determinado bairro e território e o recebimento de auxílio financeiro pela família.

As falas expuseram conflitos frente aos agentes da segurança, além de um temor pelo espaço público e a negação do direito de ir e vir de uma forma tranquila. Os adolescentes discutiram também sobre as violências nos territórios, como o abuso sexual de crianças, que não é tolerado pelo crime organizado, além do alto número de casos de violência contra a mulher, que demonstraram discordar das atitudes de tais parceiros.

Foram constatadas ainda outras violências intrafamiliares e abusos sexuais. Algumas falas abordaram o abuso sexual contra crianças e adolescentes e como a comunidade ao redor deles reage frente a esse tipo de situação. A violência contra a mulher também entra em questão e na fala manifesta, ficava claro o quanto este tipo de violência tem se disseminado socialmente entre diversas culturas, realidades e sujeitos.

No que estabelece o ECA ${ }^{1}$, nenhuma destas situações e condições de vulnerabilidades e violação de direitos deveriam ocorrer e, principalmente, descaracterizar a forma como o Estado e a polícia ainda age com os adolescentes, que ainda é permeada pela punição, agressão, exclusão e negação de direitos. E neste sentido, a população carcerária no país atinge altos índices e, com os adolescentes, não é diferente, além da alta taxa de homicídios contra a população adolescente, negra e do sexo masculino no Brasil ${ }^{27}$.

0 tráfico é um sistema muito mais amplo dentro de uma sociedade, cujo intuito é o dinheiro e altos ganhos de capital, por meio do comércio. São bens e posses que falam pelo sujeito. 0 poder de consumo é o principal desejo dos adolescentes, frente ao capitalismo exacerbado $^{28}$. Os jovens são apenas a base de um sistema muito mais amplo, em que nem sempre os seus líderes estão passíveis de serem responsabilizados pelos seus atos perante a lei. E, neste sentido, uma violação acarreta outra, e a violência gera violência, no entanto, a sociedade só tende a culpabilizar os sujeitos e as famílias mais pobres e vulneráveis, se ausentando de sua responsabilidade.

Os adolescentes em seus discursos deixaram bem claro os tipos de violência com que convivem: a violência física, moral e psicológica são as mais constantes, em especial a última, que acontece o tempo todo e em qualquer lugar ${ }^{29}$. Questionam a discriminação, a desigualdade e a falta de liberdade. Uma sociedade, da qual o "filho do rico" é tratado muito diferente do "filho do pobre".

O ECA ${ }^{1}$ tem por intuito garantir direitos e fazer com que a proteção social e integral seja garantida ao sujeito em desenvolvimento. Há ainda muita desinformação e negação de direitos essenciais. Neste sentido, é preciso empoderar os sujeitos para que possam dialogar e enfrentar tais violências e violações.

Os direitos devem ser garantidos em sua totalidade, e os deveres, colocados em prática por parte da responsabilidade dos adolescentes e seus familiares. Os sujeitos da pesquisa desejam ter voz ativa num processo de liberdade e autonomia, para que possam ter controle sobre suas próprias vidas e existência. O PIA, que é construído com o técnico de referência, se 
torna um diferencial no atendimento para que o adolescente em conflito com a lei e sua família participem ativamente do processo de cumprimento de medidas socioeducativas ${ }^{2}$.

A violência é mediadora das ações e dos discursos, e o quanto este cenário se reproduz de forma ampliada pela ausência do Estado Social para estabelecer políticas públicas, que reafirmam a judicialização da pobreza, a punição e a repressão.

Quando se fala na atenção aos adolescentes e seus familiares, deve-se pensar na centralidade deste estudo, que é a Cultura da Paz, que só é possível mediante a existência de políticas públicas afirmativas que resgatem os direitos sociais e provoquem uma mudança nos discursos, tornando a paz mediadora das realidades e vivências.

Há a necessidade de se compreender as demandas e as falas, e incluir os sujeitos no processo de tomada de decisões previsto no sistema democrático ${ }^{30}$. E esta participação só é possível quando há compromisso das políticas públicas, do trabalho em rede e da preocupação com o bem-estar e qualidade de vida.

\section{CONCLUSÃo}

Dentro do cenário brasileiro, a promoção da saúde na perspectiva de sua política deve ser estabelecida como uma prioridade ao se relacionar com diversas políticas públicas que, em conjunto, possibilitam o alcance da Cultura da Paz e sua efetividade nos territórios. Deste modo, a proteção social só é alcançada com um trabalho em rede e a valorização da justiça social.

Este estudo possui limitações para efetuar generalizações sobre as categorias aqui discutidas, pois seu foco está direcionado apenas aos participantes da pesquisa. Porém, abre portas para novas pesquisas sobre a temática da Cultura da Paz, as relações familiares e os adolescentes em conflito com a lei que venham a ser desenvolvidas em diversos outros espaços e territórios, buscando expor as diversas faces das realidades brasileiras.

Nas construções familiares dos adolescentes em cumprimento de medidas socioeducativas pesquisados, aponta-se a importância da implementação da Cultura da Paz, perpassando pela capacitação dos profissionais, estruturação dos serviços e órgãos, democratização do processo de tomada de decisão e participação ativa de todos os atores.

\section{REFERÊNCIAS}

1. Presidência da República (Brasil). Lei №. 8.069, de 13 de julho de 1990. Dispõe sobre o Estatuto da Criança e do Adolescente e dá outras providências [Internet]. Brasília, DF: Presidência da $\quad$ República; $1990 . \quad$ Disponível em: http://www.planalto.gov.br/ccivil_03/leis/18069.htm

2. Ministério da Saúde (Br). Política Nacional de Promoção da Saúde (PNPS): anexo I da Portaria de Consolidação no 2, de 28 de setembro de 2017, que consolida as normas sobre as políticas nacionais de saúde do SUS [Internet]. Brasília, DF: Ministério da Saúde; 2018. 40p. Disponível

em:

http://bvsms.saude.gov.br/bvs/publicacoes/politica_nacional_promocao_saude.pdf

3. Cronemberger IHGM, Teixeira SM. O sistema de proteção social brasileiro, política de assistência social e atenção à família. Pensando Fam. [Internet]. 2015 [citado em 03 abr 2020]; 19(2):132-47. Disponível em: http://pepsic.bvsalud.org/pdf/penf/v19n2/v19n2a11.pdf

4. Secco M, Lima EP. Justiça restaurativa - problemas e perspectivas. Rev Direito Práx. [Internet]. 2018 [citado em 04 abr 2020]; 9(1):443-60. DOI: https://doi.org/10.1590/21798966/2018/32715

5. Carta de Ottawa: promoção de saúde nos países industrializados. In: $1^{\text {a }}$ Conferência Mundial de Promoção da Saúde [Internet]. Ottawa: OMS; 1986 [citado em 03 abr 2020]. Disponível em: https://bvsms.saude.gov.br/bvs/publicacoes/carta_ottawa.pdf 
6. World Health Organization. Transforming our world: the 2030 Agenda for Sustainable Development [Internet]. Geneva: WHO; 2015 [citado em 02 abr 2020]. Disponível em: https://sustainabledevelopment.un.org/post2015/transformingourworld

7. Madaleno R. Curso de direito da família. 6ed. Rio de Janeiro: Forense; 2015. 1361p.

8. Santana CVMOR. A família na atualidade: novo conceito de família, novas formações e o papel do IBDFAM (Instituto Brasileiro de Direito de Família) [Internet]. monografia. Aracaju: Universidade Tiradentes; 2015 [citado em 03 abr 2020]. Disponível em: https://openrit.grupotiradentes.com/xmlui/handle/set/1649

9. Ministério da Cidadania (Brasil). Centro de Referência Especializado de Assistência Social CREAS. Brasília, DF: Ministério da Cidadania, 2015.

10. Gil AC. Como elaborar projetos de pesquisa. 4ed. São Paulo: Atlas; 2002. 176p.

11. Marcondes MER. Proposições metodológicas para o ensino de química: oficinas para a aprendizagem da ciência e o desenvolvimento da cidadania. Em Extensão [Internet]. 2008 [citado em 05 abr 2020]; 7:67-77. Disponível em: http://www.seer.ufu.br/index.php/revextensao/article/viewFile/20391/10861

12. Minayo MCS. O desafio do conhecimento: pesquisa qualitativa em saúde. 14ed. São Paulo: Hucitec; 2014. 416p.

13. Bonfim, LA, tradutora. Grupos focais: conceitos, procedimentos e reflexões baseadas em experiências com o uso da técnica em pesquisas de saúde. Physis [Internet]. 2009 [citado em 05 abr 2020]; 19(3):777-96. DOI: https://doi.org/10.1590/S0103-73312009000300013

14. Minayo MCS, Deslandes SF, Gomes R. Pesquisa Social: teoria, método e criatividade. 21ed. Petrópolis: Editora Vozes; 2002. 80p.

15. Gil AC. Métodos e técnicas de pesquisa social. 6ed. São Paulo: Atlas; 2008. 220p.

16. Campos CJG. Método de análise de conteúdo: ferramenta para a análise de dados qualitativos no campo da saúde. Rev Bras Enferm. [Internet]. 2004 [citado em 05 abr 2020]; 57(5): 611-4. DOI: https://doi.org/10.1590/S0034-71672004000500019

17. Rasera EF, Japur M. Contribuições do pensamento construcionista para o estudo da prática grupal. Psicol Reflex Crit. [Internet]. 2001 [citado em 04 abr 2020]; 14(1):201-9. DOI: https://doi.org/10.1590/S0102-79722001000100017

18. Gergen KJ. 0 movimento do construcionismo social na psicologia moderna. INTERthesis [Internet]. 2009 [citado em 05 abr 2020]; 6(1):299-35. DOI: https://doi.org/10.5007/18071384.2009v6n1p299

19. Medeiros FC, Paiva IL. A convivência familiar no processo socioeducativo de adolescentes em privação de liberdade. Estud Pesqui Psicol. [Internet]. 2015 [citado em 03 abr 2020]; 15(2):568-86. Disponível em: http://pepsic.bvsalud.org/pdf/epp/v15n2/v15n2a08.pdf

20. Sganzerla IM, Levandowski DC. Ausência paterna e suas representações para o adolescente: análise da literatura. Psicol Rev. [Internet]. 2010 [citado em 04 abr 2020]; 16(2): 295-309. DOI: https://doi.org/10.5752/P.1678-9563.2010v16n2p295

21. Ramires VRR, Falcke D. Fatores de risco e proteção para vínculos familiares no sul do Brasil. Psicol Teor Prat. [Internet]. 2018 [citado em 03 abr 2020]; 20(1):126-40. DOI: https://dx.doi.org/10.5935/1980-6906/psicologia.v20n1p126-140

22. Ministério do Desenvolvimento Social (Brasil). Política Nacional de Assistência Social. Brasília, DF: Ministério do Desenvolvimento Social; 2005. 178p.

23. Oliveira CBE, Oliva OB, Arraes J, Galli CY, Amorim G, Souza LA. Socioeducação: origem, significado e implicações para o atendimento socioeducativo. Psicol Estud. [Internet]. 2016 [citado em 05 abr 2020]; 20(4):575-8. DOI: https://doi.org/10.4025/psicolestud.v20i4.28456 24. Silveira JZA. A proteção integral e o melhor interesse da criança e do adolescente: uma abordagem à luz da Lei N. 8.069/90 [Internet]. monografia. Rio de Janeiro: UniRio; 2015 [citado em 05 de abr 2020]. Disponível em: http://www.unirio.br/ccjp/arquivos/tcc/2015-1jessica-ziegler

25. Minayo MCS. Violência e saúde. Rio de Janeiro: Editora Fiocruz; 2006. 132p. 
26. Azevedo E, Pelicioni MCF, Westphal MF. Práticas intersetoriais nas políticas públicas de promoção de saúde. Physis [Internet]. 2012 [citado em 03 abr 2020]; 22(4):1333-56. DOI: https://doi.org/10.1590/S0103-73312012000400005

27. Monitor da Violência. Superlotação aumenta e número de presos provisórios volta a crescer no Brasil. G1 [Internet]. 2019 [citado em 05 abr 2020]. Disponível em: https://g1.globo.com/monitor-da-violencia/noticia/2019/04/26/superlotacao-aumenta-enumero-de-presos-provisorios-volta-a-crescer-no-brasil.ghtml

28. Zecchin GB, Andrade MFR. Sociedade do consumo e o papel da educação. Estud Aplic Educ. [Internet]. 2017 [citado em 02 abr 2020]; 2(3):75-87. DOI: https://doi.org/10.13037/reae.vol2n3.4388

29. Souto DF, Zanin L, Ambrosano GMB, Flório FM. Violência contra crianças e adolescentes: perfil e tendências decorrentes da Lei 13.010. Rev Bras Enferm. [Internet]. 2018 [citado em 05 abr 2020]; 71(Suppl 3):1237-46. DOI: http://dx.doi.org/10.1590/0034-7167-2017-0048

30. Mezzalira C, Comerlatto D. A família no âmbito das políticas públicas de saúde e assistência social [Internet]. In: 1ํo Congresso Internacional de Política Social e Serviço Social: Desafios Contemporâneos, $2^{\circ}$ Seminário Nacional de Território e Gestão de Políticas Sociais, 10 Congresso de Direito à Cidade e Justiça Ambiental, 2015, Londrina. Londrina, PR: UEL; 2015. p. 1-14.

\section{CONTRIBUIÇÕES}

Luciano Aparecido Pereira Junior contribuiu na concepção, coleta e análise de dados e, redação. Matheus Colombari Caldeira e Thercius Oliveira Tasso atuaram na redação e revisão. Regina Célia de Souza Beretta participou na concepção, análise de dados, redação e revisão.

\section{Como citar este artigo (Vancouver)}

Pereira Junior LA, Caldeira MC, Tasso TO, Beretta RCS. A fragilização dos vínculos familiares dos adolescentes em liberdade assistida. REFACS [Internet]. 2020 [citado em inserir dia, mês e ano de acesso]; 8(Supl. 3):975-986. Disponível em: inserir link de acesso. DOI: inserir link do DOI.

\section{Como citar este artigo (ABNT)}

PEREIRA JUNIOR, L. A.; CALDEIRA, M. C.; TASSO, T. O.; BERETTA, R. C. S. A fragilização dos vínculos familiares dos adolescentes em liberdade assistida. REFACS, Uberaba, MG, v. 8, p. 975-986, 2020. Supl. 3. Disponível em: inserir link de acesso. Acesso em: inserir dia, mês e ano de acesso. DOI: inserir link do DOI.

\section{Como citar este artigo (APA)}

Pereira, L.A., Jr., Caldeira, M.C., Tasso, T.O., \& Beretta, R.C.S. (2020). A fragilização dos vínculos familiares dos adolescentes em liberdade assistida. REFACS, 8(Supl. 3), 975-986. Recuperado em inserir dia, mês e ano de acesso de inserir link de acesso. DOI: inserir link do DOI. 